Article

\title{
Performance Characterization of Waterborne Epoxy Resin and Styrene-Butadiene Rubber Latex Composite Modified Asphalt Emulsion (WESAE)
}

\author{
Jianhua Yang ${ }^{1}$, Zhengqi Zhang ${ }^{1, *}$, Ying Fang ${ }^{1}$ and Yaofei Luo ${ }^{2}$ \\ 1 Key Laboratory of Road Structure \& Material Ministry of Transport, Chang'an University, Xi'an 710064, \\ China; jianhua_chd@126.com (J.Y.); fangying_chd@126.com (Y.F.) \\ 2 School of Civil Engineering and Architecture, Zhengzhou University of Aeronautics, Zhengzhou 450046, \\ China; hpulyf@163.com \\ * Correspondence: z_zhengqi@126.com
}

Received: 16 March 2020; Accepted: 2 April 2020; Published: 4 April 2020

\begin{abstract}
Neat asphalt emulsions have poor physicochemical properties. In order to endow neat asphalt emulsions with excellent physicochemical properties and broaden their application as pavement, this study adopted the composite modification method using waterborne epoxy resin (WER) and styrene-butadiene rubber (SBR) latex. Firstly, a waterborne-epoxy-SBR composite modified asphalt emulsions (WESAEs) with different amounts of WER were prepared, and the storage stability, workability, and residual properties were characterized with a series of tests. Then, the performance of the WESAEs was comprehensively evaluated by multiobjective gray target decision-making method, through which the optimal amount of WER in WESAE was determined. Lastly, the modification mechanism of WER was revealed by Fourier-transform infrared spectroscopy test. The results show that the incorporation of WER improves the high-temperature performance, thermal stability, rheological property, and adhesion of the SBR modified asphalt emulsion (SBRAE) residues. However, an excessive amount of WER will adversely affect the storage stability, particle distribution uniformity, and workability of the WESAE binder. The WESAE with 3\% WER showed the best comprehensive performance; thus, the optimal amount of WER is $3 \%$ of the weight of the WESAE. Additionally, modification of the SBRAE by WER is a physical blending process, meaning no chemical reaction occurs in the blending process.
\end{abstract}

Keywords: waterborne epoxy resin (WER); SBR modified asphalt emulsion (SBRAE); storage stability; workability; evaporation residue performance; modification mechanism

\section{Introduction}

Asphalt emulsions have been widely used in road construction. For example, they are used as binders for microsurfacing and for slurry seals, and for fog seal, prime coat, and tack coat purposes [1,2]. An asphalt emulsion contains asphalt particles dispersed in water, and its viscosity is low enough to be conveniently handled at ambient temperature. Therefore, it does not need to be heated as hot-mixed asphalt does, thus having energy conservation and environmental protection benefits. However, in actual engineering, neat asphalt emulsions show relatively poor performance in terms of high-temperature conditions, thermal stability, mechanical properties, and adhesion with aggregates $[3,4]$. Therefore, they cannot meet the high performance demands and are mainly confined to lower seal coat and non-structural pavement layer applications.

It is necessary to improve the performance of neat asphalt emulsions and broaden their applications in the field. To achieve these goals, a styrene-butadiene rubber (SBR) latex is mainly used to modify the asphalt emulsion at present. However, relevant research has shown that SBR latex especially improves 
the low-temperature performance of asphalt emulsion residues and causes small improvements in terms of high-temperature performance, temperature sensitivity, and adhesion in asphalt emulsion residues [5-7]. As such, SBR modified asphalt emulsions still do not meet the performance requirements for materials used in special climate conditions, such as in high temperatures or with large temperature changes in a short time. In addition, the incorporation of waterborne epoxy resin (WER) into the asphalt emulsion is also a feasible modification approach. Its addition can impart the asphalt emulsion residue with good high-temperature performance, temperature sensitivity, and adhesion [8,9]. WER is a thermosetting material, so its brittle characteristics at low temperature should be improved in the modification process [10].

In view of this, composite modification using both WER and SBR latex is considered as a potential way to improve the performance of asphalt emulsions. The modification of asphalt emulsions with both WER and SBR latex is a relatively new method, and the relevant research is very limited. In previous studies, Zhang et al. [11] and Li et al. [12] prepared a WER and SBR composite modified asphalt emulsion and measured its residual properties, concluding that the composite modified asphalt emulsion residue was superior to a SBR modified asphalt emulsion in terms of high-temperature performance and thermal stability. Zhang et al. [13] prepared the WER and SBR composite modified asphalt emulsion as a tack coat and evaluated its residual high-temperature and adhesive performance. Their results showed that the two properties of the composite modified asphalt emulsion residue increased significantly. However, the current research is still not comprehensive enough in terms of performance characterization for the WER and SBR composite modified asphalt emulsion itself or for its evaporation residue.

The objective of this study is to comprehensively characterize the properties of the WER and SBR composite modified asphalt emulsion based on laboratory tests. To achieve this objective, waterborne-epoxy-SBR composite modified asphalt emulsions (WESAEs) with different amounts of WER were prepared, and their storage stability, workability, and residual properties were analyzed and assessed. Next, the performance of WESAEs was comprehensively evaluated and the modification mechanisms of WER samples was revealed. The research findings provide theoretical support for the practical production and application of a WESAE, which has great significance in promoting the application of WESAEs in highway engineering.

\section{Materials}

\subsection{SBR Modified Asphalt Emulsion (SBRAE)}

SBRAE prepared by emulsifying Kunlun-90 asphalt was used in the experiment. The SBR latex was added at $3 \%$ of the weight of the SBRAE, because 3\% SBR latex achieved a higher performance-to-content ratio according to the previous studies $[13,14]$. The technical properties of the SBRAE were tested according to the Standard Test Methods for Bitumen and Bituminous Mixtures for Highway Engineering (JTG E20-2011) for China (hereinafter referred to as JTG E20-2011), with results shown in Table 1. As can be seen from Table 1, the technical properties of the SBRAE used in the experiment meet the technical requirements. 
Table 1. Technical properties of the styrene-butadiene rubber modified asphalt emulsion (SBRAE).

\begin{tabular}{|c|c|c|c|c|}
\hline \multicolumn{2}{|c|}{ Contents } & Measured Values & $\begin{array}{c}\text { Technical } \\
\text { Requirements }\end{array}$ & Test Methods \\
\hline \multicolumn{2}{|c|}{ Remaining amount on $1.18 \mathrm{~mm}$ sieve (\%) } & 0.01 & $\leq 0.1$ & Т 0652 \\
\hline \multicolumn{2}{|c|}{ Standard viscosity (s) } & 22 & $12-60$ & Т 0621 \\
\hline \multicolumn{2}{|c|}{$1 \mathrm{~d}$ storage stability $(\%)$} & 0.7 & $\leq 1$ & Т 0655 \\
\hline \multicolumn{2}{|c|}{$5 \mathrm{~d}$ storage stability $(\%)$} & 4.2 & $\leq 5$ & Т 0655 \\
\hline & Content (\%) & 61.7 & $\geq 60$ & Т 0651 \\
\hline \multirow[t]{3}{*}{$\begin{array}{l}\text { Evaporation } \\
\text { residue }\end{array}$} & $\begin{array}{c}\text { Penetration at } 25^{\circ} \mathrm{C} \\
(0.1 \mathrm{~mm})\end{array}$ & 66 & 40-100 & Т 0604 \\
\hline & Softening point $\left({ }^{\circ} \mathrm{C}\right)$ & 55.0 & $\geq 53$ & Т 0606 \\
\hline & Ductility at $5{ }^{\circ} \mathrm{C}(\mathrm{cm})$ & $>100$ & $\geq 20$ & Т 0605 \\
\hline
\end{tabular}

\subsection{Waterborne Epoxy Resin (WER) and Curing Agent}

WER BH-653 and the corresponding BH-532 curing agent were purchased from China Dongguan Guangtong Chemical Products Co., Ltd. Their technical indicators are shown in Table 2. Table 2 shows that the WER is strongly acidic, with the same acid-base properties as cationic asphalt emulsions. Thus, the WER does not cause demulsification due to acid-base neutralization reaction when it is incorporated into a cationic asphalt emulsion.

Table 2. Technical indicators of the waterborne epoxy resin (WER) and the corresponding curing agent (provided by the merchant).

\begin{tabular}{ccccccc}
\hline Items & Types & Appearances & $\begin{array}{c}\text { Resin } \\
\text { Content (\%) }\end{array}$ & $\begin{array}{c}\text { Epoxy } \\
\text { Equivalent } \\
\text { (g/mol) }\end{array}$ & $\begin{array}{c}\text { Amine } \\
\text { Value (mg } \\
\text { KOH/g) }\end{array}$ & $\begin{array}{c}\text { pH } \\
\text { Value }\end{array}$ \\
\hline WER & $\begin{array}{c}\text { Modified by } \\
\text { chemical method } \\
\text { Epoxy-amine } \\
\text { Cudduct }\end{array}$ & Milk white & $60 \pm 2$ & $180-230$ & - & $3.5 \pm 1$ \\
\hline
\end{tabular}

\subsection{Waterborne-Epoxy-SBR Composite Modified Asphalt Emulsion (WESAE)}

The WESAE was obtained by modifying the preprepared SBRAE with WER. The preparation process for WESAE can be summarized into three steps. In the first step, the preprepared SBRAE was evenly stirred and $500 \mathrm{~g}$ was poured into a beaker. Next, the required weights of the WER and curing agent were successively added into the beaker, and their blend was initially stirred using a glass rod. Lastly, the blend was stirred using a propeller impeller agitator for $15 \mathrm{~min}$ at $500 \mathrm{r} / \mathrm{min}$. The WER was added at four strengths $(1 \%, 2 \%, 3 \%$, and $4 \%)$ by weight of WESAE, and the weight ratio of the WER and the curing agent was 1:1.

\section{Experiment Methods}

In order to comprehensively characterize the storage, workability, and residual properties of the WESAE binder and to reveal the modification mechanism of WER, the following tests were performed.

\subsection{Storage Stability Test}

The one-day storage stability test for WESAE was conducted in accordance with method T 0655 in JTG E20-2011. In the test, the filtered and stirred WESAE was first injected into a storage stability test tube and left for one day. Next, the emulsions from the upper and lower branch pipes were obtained and the contents of their evaporation residues were measured. The difference in evaporation residue contents was calculated as the evaluation index for WESAE storage stability. For each WESAE sample, the test result was the average of three repeated trials. The test temperature was $25^{\circ} \mathrm{C}$. 


\subsection{Fluorescence Microscope Test}

A fluorescence microscope test was carried out to analyze the storage stability of the WESAE from a microscopic perspective. To conduct the test, the emulsion was first dropped onto a glass slide and covered with a cover glass. Then, it was observed before demulsification using a LW300LFT-LED epifluorescence microscope and the micromorphology photos of the WESAE were captured using ISCapture software, which came with the microscope. Meanwhile, 200 representative emulsion microspheres were captured and their diameters were measured using the ISCapture software; thus, the particle size distribution of WESAE was obtained. The micromorphology and particle size distribution were used to evaluate the storage stability of the WESAE from a microscopic perspective. Additionally, during the observation, the microscope was configured with an objective lens with 40 times magnification, an eyepiece with 10 times magnification, a blue filter, and a blue LED light source.

\subsection{Standard Viscosity Test}

According to T 0621 in JTG E20-2011, the standard viscosity of the WESAE was tested. In the experiment, the WESAE was first injected into a sample holding tube with a hole at the bottom (hole diameter of $4 \mathrm{~mm}$ ) and kept at $25^{\circ} \mathrm{C}$ for $30 \mathrm{~min}$. Then, $50 \mathrm{~mL}$ was allowed to flow out, while the time taken for this to happen was recorded using a stopwatch. This time was taken as the standard viscosity for each sample. Three repeated tests were carried out for each sample and the final result was the average of the three tests.

\subsection{Residue Tests}

Penetration, softening point, differential scanning calorimetry, dynamic shear rheological, and adhesion tests were conducted to characterize the properties of the WESAE evaporation residue.

\subsubsection{Penetration and Softening Point Tests}

The penetration and softening point tests were carried out to analyze the high-temperature performance of the WESAE residue. These tests were operated in alignment with those in JTG E20-2011. Due to the thermosetting properties of the WER, continuous stirring destroys the three-dimensional network structure that is formed by curing in the process of obtaining the WESAE residue, so the modification effect of the WER cannot be reflected $[15,16]$. Accordingly, a one-time casting method was used to obtain the WESAE residue. Specifically, the WESAE was first evaporated until its weight dropped to $80 \%$ of the initial weight, then it was poured into the test mold and placed in an oven to obtain the evaporation residue. In order for the water to evaporate completely, the evaporation process included $6 \mathrm{~h}$ of evaporation at $80^{\circ} \mathrm{C}$, followed by $4 \mathrm{~h}$ of evaporation at $135^{\circ} \mathrm{C}$. Li et al. [17] also used a similar method to acquire a waterborne epoxy asphalt emulsion residue. After the residue was obtained, its penetration and softening point were tested according to the JTG E20-2011 specifications. The results were the means of three replicate tests.

\subsubsection{Differential Scanning Calorimetry (DSC) Test}

The differential scanning calorimetry (DSC) test was performed to measure the temperature sensitivity of the WESAE evaporation residue, using a power compensation differential scanning calorimeter manufactured by NETZSCH Company in Germany [18]. In the test, a small amount of emulsion was first evaporated at $80{ }^{\circ} \mathrm{C}$ in an oven to obtain the evaporation residue. Next, in the temperature range of 30 to $150{ }^{\circ} \mathrm{C}$, the residue was subjected to the DSC test at a heating rate of $10^{\circ} \mathrm{C} / \mathrm{min}$ (the purge and shielding nitrogen were controlled at 50 and $20 \mathrm{~mL} / \mathrm{min}$, respectively) [19]. Thus, the thermal curves were drawn by the thermal analyzer. The thermal curve results for each sample were the average of three replicate tests. After obtaining the curves, Origin software was run on the curves to obtain three important parameters used to evaluate the temperature sensitivity of each 
sample. The three parameters were the enthalpy per unit sample mass, temperature corresponding to the highest point of the endothermic peak, and temperature range of the endothermic peak.

\subsubsection{Dynamic Shear Rheological (DSR) Test}

A SmartPave 102 dynamic shear rheometer produced by Anton Paar in Austria was applied to assess the rheological property of the WESAE evaporation residue [20]. All samples were tested with a $25 \mathrm{~mm}$ diameter parallel plate and $1 \mathrm{~mm}$ spacing, and each sample was subjected to three repeated tests. In the experiment, the WESAE was first evaporated to $80 \%$ of its original weight, and then it was poured into a silicone mold and evaporated in an oven to obtain the evaporation residue (evaporation conditions were the same as the penetration and softening point tests). Next, the residue was subjected to a temperature sweep test within a temperature range of 52 to $82{ }^{\circ} \mathrm{C}(12 \%$ shear strain and $10 \mathrm{rad} / \mathrm{s}$ shear rate); thus, the complex shear modulus $\mathrm{G}^{*}$ and phase angle $\delta$ were measured in the temperature range. Then, the storage modulus $G^{\prime}\left(G^{\prime}=G^{*} \cdot \cos \delta\right)$, loss modulus $G^{\prime \prime}\left(G^{\prime \prime}=G^{*} \cdot \sin \delta\right)$, and rutting factor $G^{*} / \sin \delta$ were calculated, and $G^{\prime} / G^{*}, G^{\prime \prime} / G^{*}$, and $G^{*} / \sin \delta$ were eventually used as evaluation indices of the viscoelastic properties of the WESAE residue. In addition, the multiple stress creep recovery (MSCR) tests were performed at 58,64 , and $70{ }^{\circ} \mathrm{C}$ on the residue according to the AASHTO T 350 specification [21,22]. At each test temperature, two stress levels of 0.1 and $3.2 \mathrm{kPa}$ were applied on the residue for twenty and ten cycles, respectively. Each cycle included $1 \mathrm{~s}$ of shear creep, followed by a $9 \mathrm{~s}$ recovery period. Afterwards, obeying the MSCR protocol, the creep recovery rate $\mathrm{R}$ and non-recoverable creep compliance $\mathrm{Jnn}_{\mathrm{nr}}$ for each stress level were calculated as evaluation indices of the WESAE residue's response to repeated shear stress.

\subsubsection{Adhesion test}

The adhesion between the WESAE and the coarse limestone aggregate was measured according to the following steps.

(a) Choose three cube-shaped aggregate particles with nominal maximum particle sizes of $19.0-31.5 \mathrm{~mm}$, then clean and dry them in an oven at $105^{\circ} \mathrm{C}$;

(b) After cooling, fasten them with thin wire in the middle one-by-one, then label and weigh them separately as $\mathrm{m}_{1}$;

(c) Immerse the three aggregate particles together in one water-filled beaker for one minute, then subsequently immerse them together in the WESAE for one minute. Next, take them out and suspend them for $24 \mathrm{~h}$ at room temperature, then weigh them as $\mathrm{m}_{2}$;

(d) Boil the three aggregate particles one-by-one for three minutes in the other beaker containing the boiling water. During the boiling stage, keep the aggregate particles in the center of the beaker. After boiling, take the aggregates out and hang them on the test stand to cool for $24 \mathrm{~h}$ at room temperature. Afterwards, weigh them as $\mathrm{m}_{3}$;

(e) Calculate the stripped rate $\alpha$ of the asphalt film after soaking according to Equation (1) and take this as the evaluation index for adhesion.

$$
\alpha=\frac{m_{2}-m_{3}}{m_{2}-m_{1}} \times 100 \%
$$

in which, $\alpha$ is the stripped rate of the asphalt film after soaking; $\mathrm{m}_{1}$ is the weight of the aggregate after cleaned and dried; $m_{2}$ is the weight of the aggregate after immersed in WESAE and dried for $24 \mathrm{~h} ; \mathrm{m}_{3}$ is the weight of the aggregate after boiled in boiling water and cooled for $24 \mathrm{~h}$.

\subsection{Fourier-Transform Infrared Spectroscopy (FT-IR) Test}

In this study, a Fourier-transform infrared spectroscopy test was used to determine whether there was a chemical reaction between the WER and the SBRAE. In this experiment, the infrared spectra of the WESAE and SBRAE were first measured, and then changes in their main functional groups were compared to analyze the modification mechanism of WER. As for the FT-IR test, the sample 
used for assessment was first prepared by $\mathrm{KBr}$ pressed-disk technique and was then scanned by the Fourier-transform infrared spectrum detector. The final result was the average of three repeated trials.

\section{Results and Discussion}

\subsection{Storage and Workability Characterization of WESAE}

Regarding the cold-mixed asphalt emulsion binder, its good storage stability and workability are the reasons for its application and popularization in practical engineering. However, with the incorporation of WER, the emulsion may flocculate and demulsify, which will adversely affect its use [23]. Therefore, the storage stability and workability of the WESAEs with $1 \%, 2 \%, 3 \%$, and $4 \%$ WER were analyzed and evaluated through the storage stability test, the fluorescence microscope test, and the standard viscosity test. For comparison, the storage stability and workability of the SBRAE were also measured.

\subsubsection{Storage Stability}

The one-day storage stability of the WESAE with different contents of WER and the SBRAE was measured according to the storage stability test. The results are shown in Figure 1.

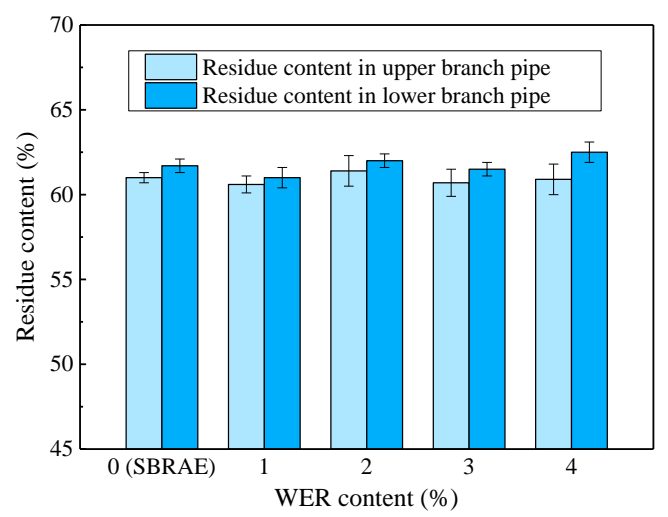

(a)

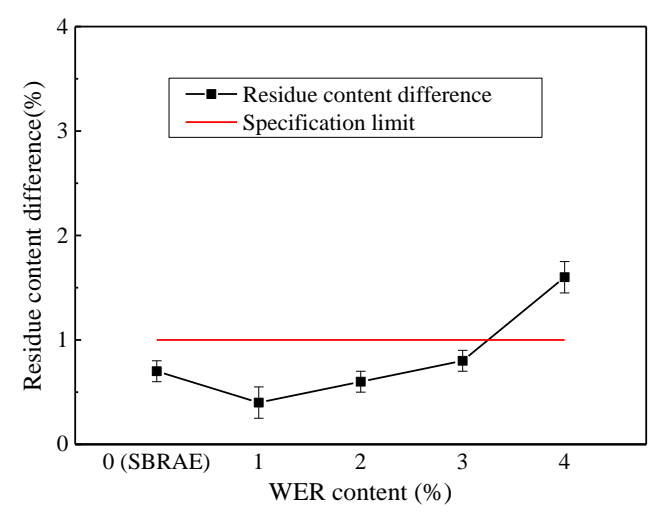

(b)

Figure 1. One-day storage stability of the waterborne-epoxy-styrene-butadiene rubber composite modified asphalt emulsion (WESAE) and SBRAE: (a) residue contents of upper and lower branch pipes; (b) change of residue content difference.

Figure 1a shows that the residue content in the lower branch pipe was larger than that in the upper branch pipe, which may be due to the slightly higher density of asphalt particles compared to water, resulting in the settlement of asphalt particles under the action of gravity during storage [24]. The residue content difference between the upper and lower branch pipes in the test tube was used to characterize the storage stability of the asphalt emulsion. Usually, a smaller residue content difference means better storage stability. In Figure $1 \mathrm{~b}$, the residue content differences of the WESAE with $1 \%$ and $2 \%$ WER were lower than that of the SBRAE. This indicates that the addition of WER can improve the storage stability of the SBRAE, but the amount needs to be limited to within a certain range. The improvement of the storage stability is attributable to the following fact [25]. When the amount of WER is lower, fewer flocculates are formed by crosslinking reaction between the WER and the curing agent; these can be evenly dispersed in the emulsion, increasing the viscosity. The increase of viscosity limits the Brownian motion of molecules, thereby improving the storage stability of the emulsion. However, when the WER content is higher, the flocculates increase and precipitate at the bottom of the test tube under the action of gravity, degrading the storage stability of the emulsion. In addition, when the content of WER reaches $4 \%$, the one-day storage stability of the WESAE exceeds the specification limit [26], indicating that the amount of WER should not be more than $4 \%$. 


\subsubsection{Particle Distribution Uniformity}

To gain an insight into the storage stability of the WESAE from a microscopic perspective, a fluorescence microscope test was conducted to observe the morphology and particle distribution of the WESAE with various WER contents. Figure 2 presents the micromorphology photos of the WESAE and SBRAE at storage times of 0 and $24 \mathrm{~h}$, and presents the particle size distribution of the WESAE and SBRAE after $24 \mathrm{~h}$ storage.

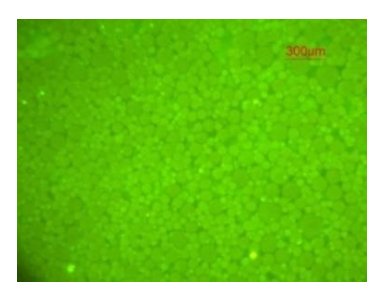

(a) $0 \%$ (SBRAE)- $0 \mathrm{~h}$

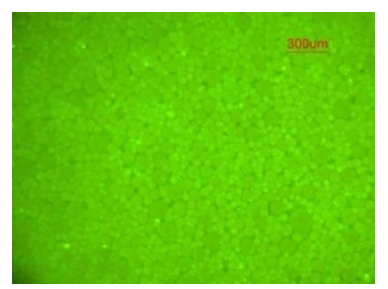

(d) $1 \%-0 \mathrm{~h}$

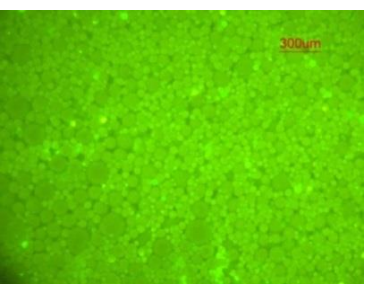

(g) $2 \%-0 \mathrm{~h}$
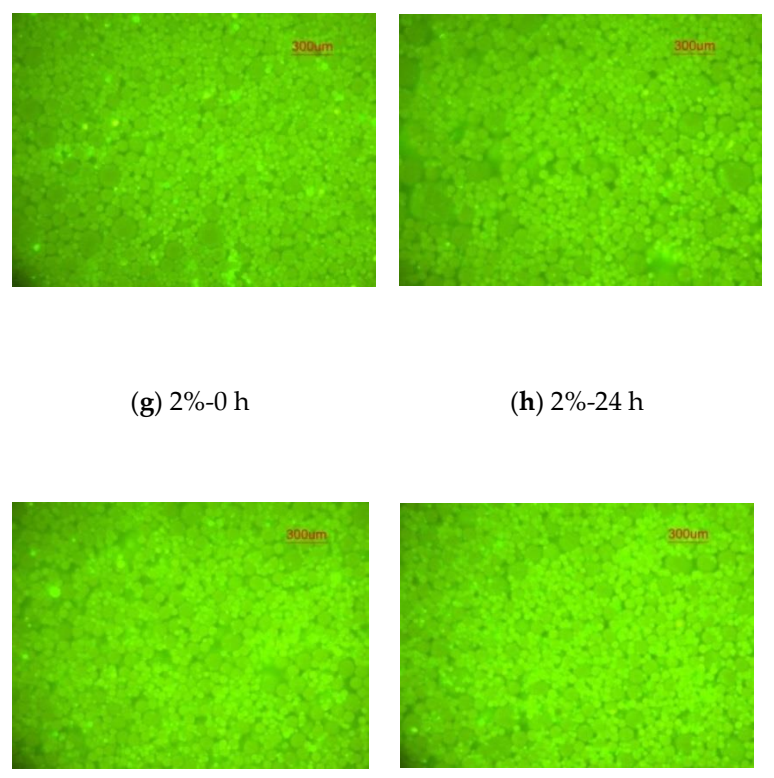

(h) $2 \%-24 \mathrm{~h}$

(k) 3\%-24 h

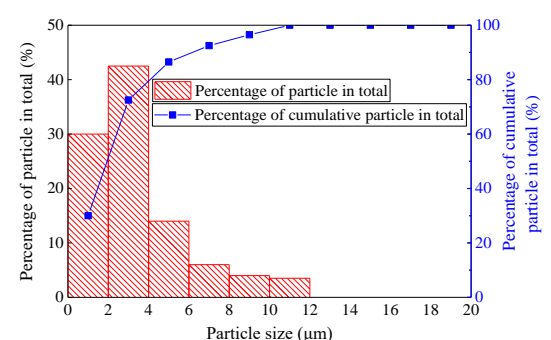

(c) $0 \%$ (SBRAE)-24 h

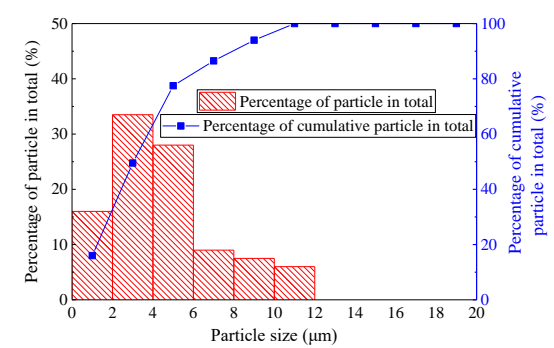

(f) $1 \%-24 \mathrm{~h}$

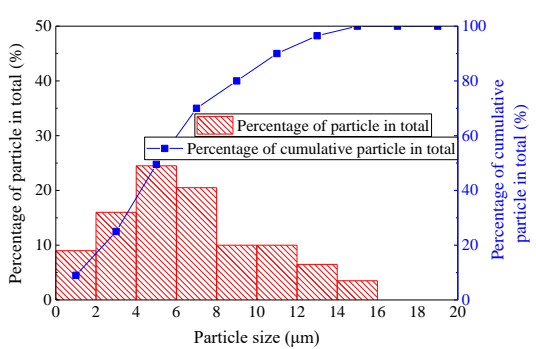

(i) $2 \%-24 \mathrm{~h}$

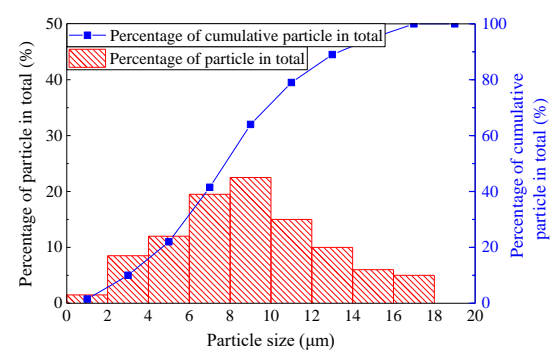

(l) $3 \%-24 \mathrm{~h}$ 


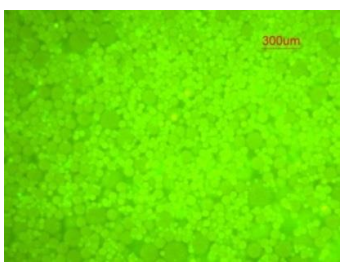

(m) $4 \%-0 \mathrm{~h}$

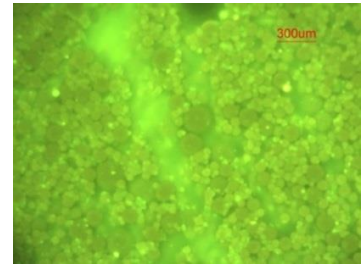

(n) $4 \%-24 \mathrm{~h}$

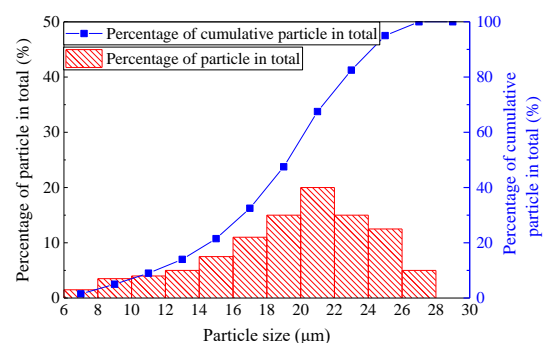

(o) $4 \%-24 \mathrm{~h}$

Figure 2. Fluorescence microscope photos and particle size distribution of the WESAE and SBRAE.

Previous studies have shown that the particle size distribution of tiny particles in an asphalt emulsion can be used to characterize the storage stability of the emulsion. In general, when the particles are small and uniform, they are not agglomerated in fluorescence microscopic photos, indicates that the asphalt emulsion has good storage stability $[27,28]$. It can be seen from Figure 2 that compared with the just-prepared WESAE and SBRAE, the particles become messy and non-uniform after they are stored for $24 \mathrm{~h}$. This is especially true for the WESAE with $4 \%$ WER, where after the $24 \mathrm{~h}$ of storage, a "void" appear in the microscope photo and the particle size distribution is obviously non-uniform (see Figure 2n). This indicates that the tiny particles in the WESAE with $4 \%$ WER have obviously agglomerated, and thus the WESAE with $4 \%$ WER has poor storage stability, which is in accordance with the results of the storage stability test. The histogram in Figure $2 \mathrm{f}, \mathrm{i}, \mathrm{l}, \mathrm{o}$ show that for the WESAE stored for $24 \mathrm{~h}$, its particles gradually becomes larger and the particle size distribution gradually grows wider with the increase of WER content, which is caused by the crosslinking action with the WER curing agent in the emulsion. For the WESAE with $4 \%$ WER, its average particle diameter and the particle diameter distribution width reach 19.456 and $22 \mu \mathrm{m}$, respectively, which are far greater than the values for the SBRAE at the same storage time. Additionally, in the experiment we observed that the yellow-green light in the fluorescence photo gradually increased with the increasing WER content, and a strong yellow-green light was observed in the fluorescence photo of the WESAE with $4 \%$ WER. This may be attributed to the increase of yellow-green light effect of the WER under the excitation action of blue light [29].

\subsubsection{Workability}

In order to analyze the workability of the WESAE binder with various WER contents, the WESAE was stored for different time periods and then its standard viscosity at different storage times was measured following the standard viscosity test. Figure 3 shows the viscosity variation values for the WESAE and SBRAE with storage time.

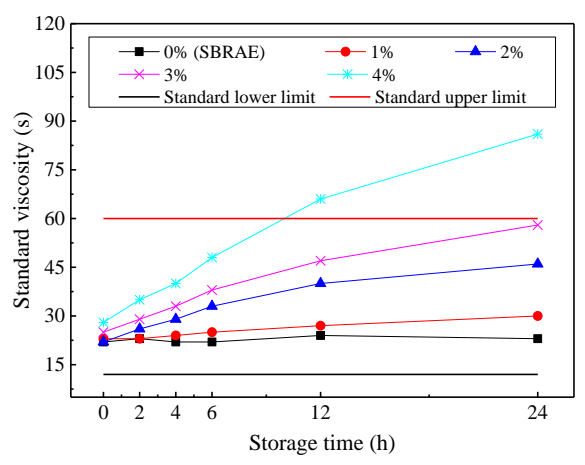

Figure 3. Viscosity variation values for the WESAE and SBRAE. 
Figure 3 shows that the viscosity values for just-prepared WESAE are similar, regardless of the content of WER. However, the viscosity of the WESAE gradually increases with storage time, and its increasing rate grows with the increase of WER content; for WESAE with $4 \%$ WER, its viscosity reaches the standard upper limit when it is stored for about $10 \mathrm{~h}$ [26]. In comparison, the viscosity of the SBRAE hardly changes with storage time; the viscosities of the other WESAE samples grow more slowly with storage time and their viscosities are lower than the standard upper limit when they are stored for $24 \mathrm{~h}$. The increase of viscosity with the storage time is attributable to the increasing polymer epoxy oligomers formed by the crosslinking reaction between the WER and the curing agent [25]. In addition, the viscosity of the WESAE increases rapidly with the increase of WER content, which may be due to the increasing concentration and contact probability of the epoxy group and the curing agent.

Minor and excessive viscosity in an asphalt emulsion both adversely affect the mixing of the emulsion and aggregate. Minor viscosity is prone to separation and flow, while excessive viscosity may mean the asphalt emulsion and aggregate do not mix uniformly. As can be seen in Figure 3, the viscosity of the WESAE with 3\% WER approaches the standard upper limit when it is stored for $24 \mathrm{~h}$. Hence, $3 \%$ can be regard as the maximum content to guarantee viscosity. WESAE with $3 \%$ WER should not be stored for more than $24 \mathrm{~h}$ after preparation, otherwise its workability will be negatively affected.

\subsubsection{Analysis of Variance Test}

To better understand the impacts of different factors on the test results, one-way analysis of variance (one-way ANOVA) was used for statistical comparison. One-way ANOVA can determine whether the influence of a factor on the test results is significant [30]. In this analysis, the WER content is the independent variable, and the residue content difference and the standard viscosity are the dependent variables. SPSS software was run to conduct the one-way ANOVA, with a significance level of $95 \%$ (i.e., $\alpha=0.05$ ) [31]. The analysis results are shown in Table 3.

Table 3. Analysis of variance (ANOVA) results for the residue content difference and standard viscosity.

\begin{tabular}{|c|c|c|c|}
\hline Properties & Dependent Variables & F-Statistics & $\begin{array}{c}\text { Significance } \\
(p \text {-Value) }\end{array}$ \\
\hline \multirow[t]{3}{*}{ Storage stability } & Residue content difference & 162.712 & 0.000 \\
\hline & \multirow{6}{*}{ Standard viscosity } & 29.042 & 0.000 \\
\hline & & 99.292 & 0.000 \\
\hline \multirow{4}{*}{ Workability } & & 236.600 & 0.000 \\
\hline & & 300.781 & 0.000 \\
\hline & & 669.289 & 0.000 \\
\hline & & 1941.857 & 0.000 \\
\hline
\end{tabular}

According to the principles of one-way ANOVA, when the $p$-value is less than or equal to 0.05 , this indicates that the factor has a significant impact on the dependent variable. It can be seen from Table 3 that the content of WER has a significant effect on the residue content difference and the standard viscosity at each storage time. Meanwhile, using SPSS software, Bonferroni's multiple comparison statistical test was carried out on the average of the test data at a 95\% significance level. Bonferroni's comparison is used for postanalysis of ANOVA and can be used to determine whether there is a difference between the test results corresponding to different levels of a certain factor. It should be noted that this factor needs to have a significant impact on the test results, as assessed by the one-way ANOVA [22]. Numerous data were generated from the Bonferroni's comparison, and due to space constraints, detailed data are not listed here. Bonferroni's comparison shows that when comparing the residue content differences in order of WER content from small to large, their differences are statistically significant. This indicates that the change of WER content can cause a change of the WESAE storage stability. When the WER reached 4\%, WESAE presented the most significant change of the storage stability as compared to SBRAE. Additionally, when comparing the standard viscosity, WESAE with $4 \%$ WER was statistically different from the WESAE with other WER contents at each storage time. 
This means that when the WER reaches $4 \%$, the standard viscosity of the WESAE changes remarkably with time.

\subsection{Performance Characterization of WESAE Evaporation Residue}

The properties of an asphalt emulsion after demulsification are crucial during its service. In order to guarantee the properties of the WESAE after breaking, the evaporation residue properties of the WESAEs with $1 \%, 2 \%, 3 \%$, and $4 \%$ WER were analyzed and evaluated. The evaporation residue properties of the SBRAE were also measured for comparison in this part.

\subsubsection{High-Temperature Performance}

According to the penetration and softening point tests, the penetration and softening points of evaporation residues for WESAE with different WER contents and for SBRAE were measured, as presented in Figure 4.

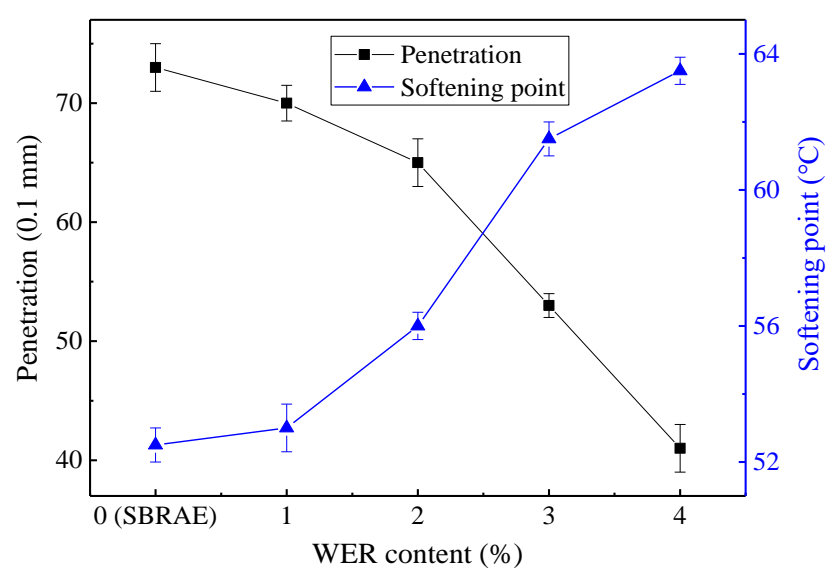

Figure 4. Penetration and softening points of evaporation residues for WESAE and SBRAE.

According to Figure 4, the penetration decreases with the increase of the WER content, while the opposite is true for the softening points. This indicates that the addition of WER improves the high-temperature performance of the SBRAE residue, which may be attributed to the irreversible chemical bond formed between the epoxy resin molecules in the emulsion during the water evaporation. The chemical bond exhibits a strong thermosetting property that restricts the molecular movement of the asphalt particles when heating, thus enhancing the high-temperature performance [12]. Moreover, the results show that the high-temperature performance of the WESAE residue increases with the increase of WER content, and when the WER content is higher than 3\%, this results in a smaller improvement of the high-temperature performance of the SBRAE residue.

\subsubsection{Temperature Sensitivity}

In order to analyze the temperature sensitivity of the WESAE residue, the thermal curve of each sample was acquired by DSC testing, as demonstrated in Figure 5 . Furthermore, for each curve, Origin software was used to extract the temperature corresponding to the highest point and the temperature range of each endothermic peak. Origin software was also run to integrate the endothermic peaks in order to obtain the enthalpy. There are two endothermic peaks in each curve, and their enthalpy values were summed as the enthalpy per unit mass. Table 4 presents the temperature, temperature range, and enthalpy per unit mass. 


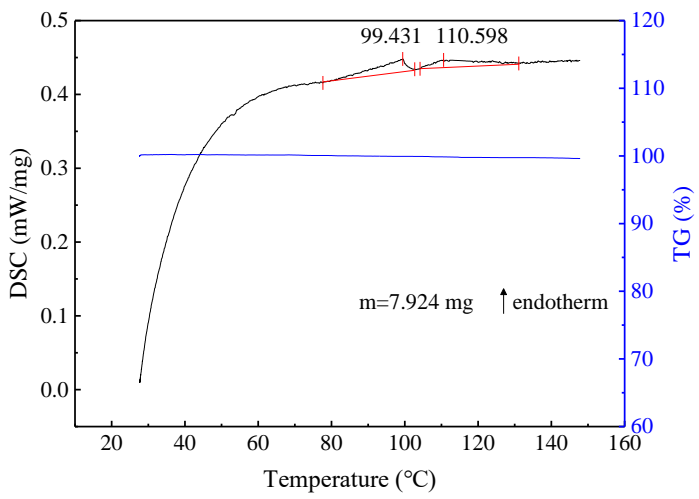

(a) $0 \%$ (SBRAE)

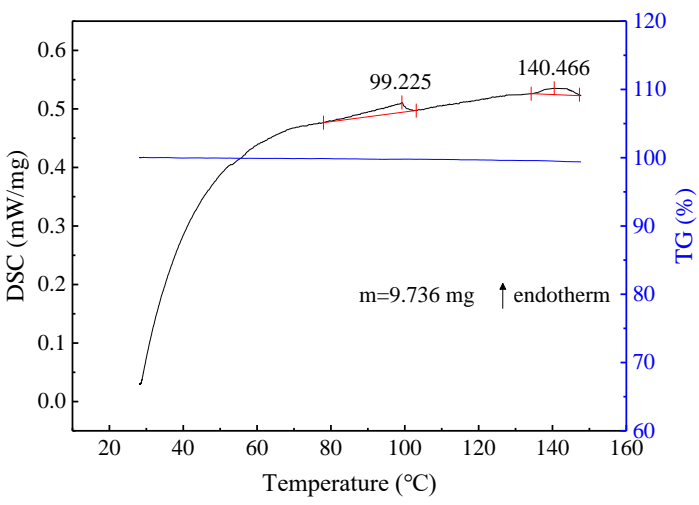

(c) $2 \%$

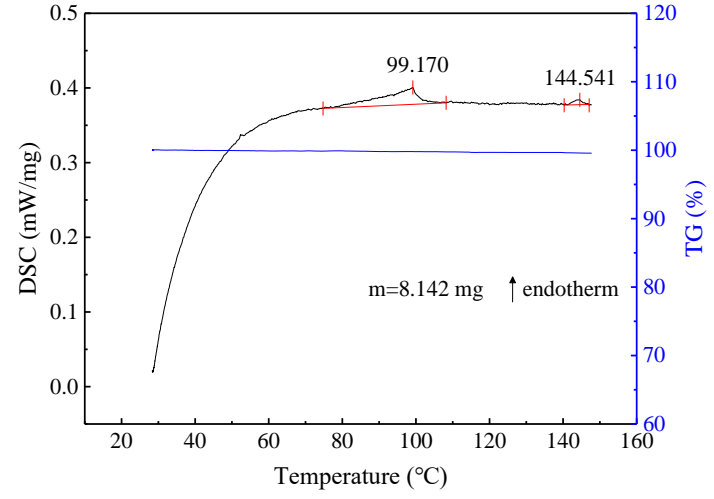

(b) $1 \%$

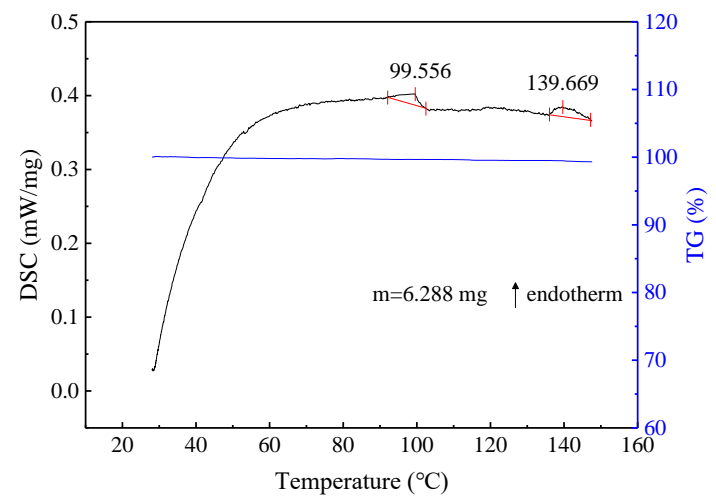

(d) $3 \%$

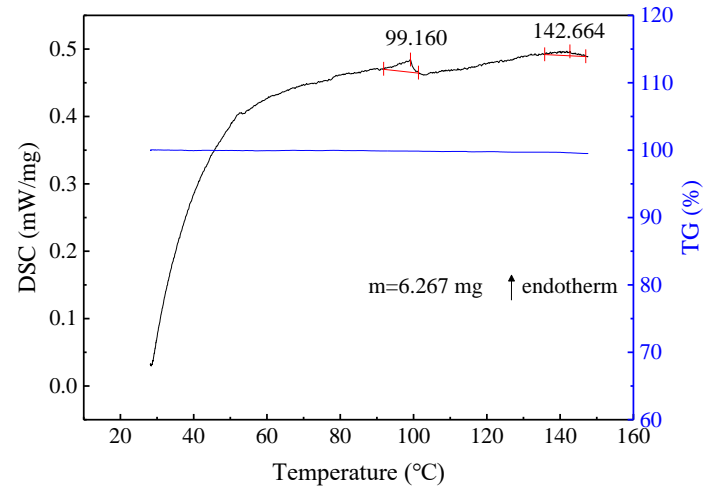

(e) $4 \%$

Figure 5. Evaporation residue thermal curves for WESAE and SBRAE.

Table 4. Evaporation residue thermal parameters for WESAE and SBRAE.

\begin{tabular}{|c|c|c|c|c|c|c|c|}
\hline \multirow[b]{2}{*}{ Samples } & \multicolumn{3}{|c|}{ Endothermic Peak 1} & \multicolumn{3}{|c|}{ Endothermic Peak 2} & \multirow{2}{*}{$\begin{array}{c}\text { Enthalpy per } \\
\text { Unit Mass } \\
(\mathrm{J} / \mathrm{g})\end{array}$} \\
\hline & $\begin{array}{c}\text { Temperature } \\
\left({ }^{\circ} \mathrm{C}\right)\end{array}$ & $\begin{array}{c}\text { Peak } \\
\text { Range } \\
\left({ }^{\circ} \mathrm{C}\right)\end{array}$ & $\begin{array}{l}\text { Enthalpy } \\
(\mathrm{J} / \mathrm{g})\end{array}$ & $\begin{array}{c}\text { Temperature } \\
\left({ }^{\circ} \mathrm{C}\right)\end{array}$ & $\begin{array}{c}\text { Peak Range } \\
\left({ }^{\circ} \mathrm{C}\right)\end{array}$ & $\begin{array}{l}\text { Enthalpy } \\
(\mathrm{J} / \mathrm{g})\end{array}$ & \\
\hline $\begin{array}{c}0 \% \\
\text { (SBRAE) }\end{array}$ & 99.431 & 77.659-102.712 & 0.197 & 110.598 & 104.154-131.104 & 0.168 & 0.365 \\
\hline $1 \%$ & 99.170 & $74.752-108.211$ & 0.265 & 144.541 & $140.282-147.087$ & 0.024 & 0.289 \\
\hline $2 \%$ & 99.225 & 77.985-103.095 & 0.185 & 140.466 & $134.228-147.307$ & 0.083 & 0.268 \\
\hline $3 \%$ & 99.556 & $92.070-102.465$ & 0.068 & 139.669 & $136.046-147.205$ & 0.083 & 0.151 \\
\hline $4 \%$ & 99.160 & 91.839-101.334 & 0.069 & 142.664 & 135.788-147.001 & 0.037 & 0.106 \\
\hline
\end{tabular}


Previous research has shown that for asphalt with good thermal stability, its DSC curve is generally flat, with a smaller endothermic peak area, narrower peak range, and lower enthalpy per unit mass in the test temperature range [27,32]. Additionally, Xu et al. [33] established the correlation between the three above parameters (temperature, peak range, and enthalpy) and the penetration index, and analyzed the correlation between the three parameters and the penetration-viscosity index, respectively. Their results showed that the maximum correlation coefficient exists between the enthalpy-penetration and the enthalpy-penetration-viscosity indices, meaning that enthalpy best characterizes the thermal stability of asphalt.

As can be seen in Table 4, for the WESAE residues, the second temperature peak increases from 110 to $140{ }^{\circ} \mathrm{C}$, which means that the addition of WER increases the phase change temperature for the SBRAE residue, thus improving its thermal stability. All the WESAE residues show melting endothermic peaks at around $99^{\circ} \mathrm{C}$ and near $140^{\circ} \mathrm{C}$ for the amine substance, which indicates that all the WESAE residues have similar physical thermal stability values. Furthermore, according to the variation of the thermo-gravimetric curve with temperature in Figure 5, it can be seen that the chemical properties of each sample are stable and that there is no weight loss caused by thermo-oxidative decomposition with the increase of temperature. In addition, the addition of WER reduces the enthalpy per unit mass (see Table 4). The enthalpy per unit mass of the WESAE residue with 3\% WER is reduced by more than $50 \%$ compared with that of the SBRAE residue, indicating that 3\% WER greatly reduces the temperature sensitivity of the SBRAE residue and endows it with good thermal stability.

\subsubsection{Rheological Properties}

(1) Temperature Scanning Analysis

The evaporation residues of the WESAE samples containing different proportions of WER and the SBRAE were prepared and subjected to DSR testing under temperature scanning mode; thus, the complex shear modulus $G^{*}$ and phase angle $\delta$ were measured. Moreover, the storage modulus $G^{\prime}$, the loss modulus $G^{\prime \prime}$ and the rutting factor $G^{*} / \sin \delta$ were calculated. Figure 6 shows the changes of $G^{\prime} / G^{*}$, $G^{\prime \prime} / G^{*}$, and $G^{*} / \sin \delta$ with scanning temperatures for each sample.

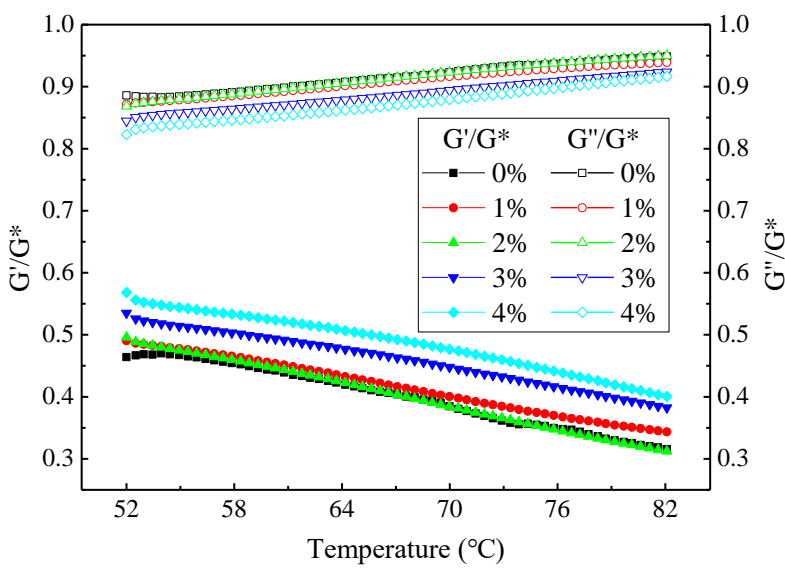

(a)

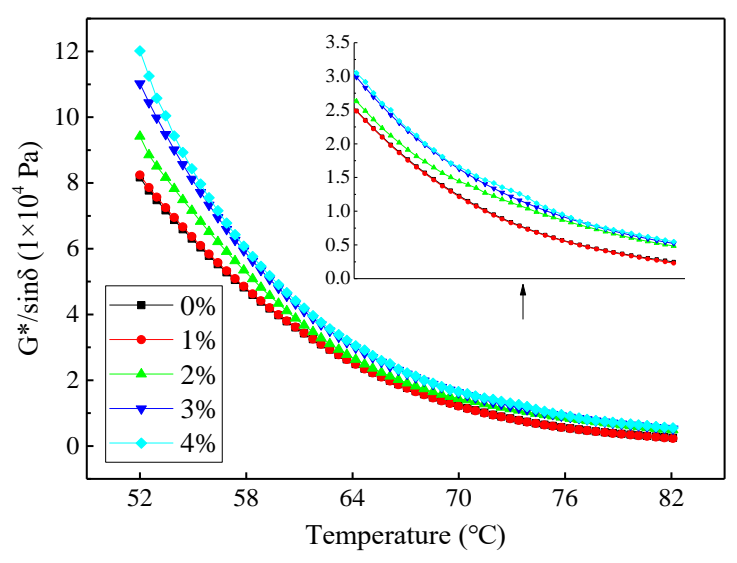

(b)

Figure 6. $G^{\prime} / G^{*}, G^{\prime \prime} / G^{*}$, and $G^{*} / \sin \delta$ of the evaporation residues for WESAE and SBRAE at different temperatures: (a) changes of $G / G^{*}$ and $G^{\prime \prime} / G^{*} ;(\mathbf{b})$ changes of $G^{*} / \sin \delta$.

$\mathrm{G}^{\prime}$ and $\mathrm{G}^{\prime \prime}$ are the real and the imaginary parts of the complex shear modulus $\mathrm{G}^{*}$, respectively. They represent the recoverable elastic portion and the irreversible viscous portion of $G^{*}$, respectively. At high temperature, asphalt binder is expected to have a larger $G^{\prime}$ and rutting factor to ensure its rutting resistance [34]. It can be seen from Figure 6a that in the whole temperature range, the WESAE residues have larger $G^{\prime} / G^{*}$ and smaller $G^{\prime \prime} / G^{*}$, which means the incorporation of WER increases the elastic component of the SBRAE residue. Moreover, the $G^{\prime \prime} / G^{*}$ value for each sample is larger than 
$\mathrm{G}^{\prime} / \mathrm{G}^{*}$ over the entire temperature range, indicating that the viscous component of each sample plays a dominant role. Additionally, Figure $6 \mathrm{~b}$ shows that the rutting factor of the WESAE residue increases with the increase of WER content. For instance, compared with the SBRAE residue, the rutting factors of the WESAE residues containing $2 \%, 3 \%$, and $4 \%$ WER increase by $15.3 \%, 35.0 \%$, and $47.1 \%$ at $52{ }^{\circ} \mathrm{C}$, respectively. It can be concluded that the addition of WER enhances the total deformation capacity of the SBRAE residue against repeated shear loads, and thus improves its high-temperature performance.

(2) MSCR Analysis

With the help of the dynamic shear rheometer, the creep recovery rate $\mathrm{R}$ and unrecoverable creep compliance $\mathrm{Jnr}_{\mathrm{nr}}$ of the evaporation residues for WESAE and SBRAE were measured at 58,64 , and $70{ }^{\circ} \mathrm{C}$ under constant stress of $0.1 \mathrm{kPa}$ and $3.2 \mathrm{kPa}$. The results are shown in Figure 7.

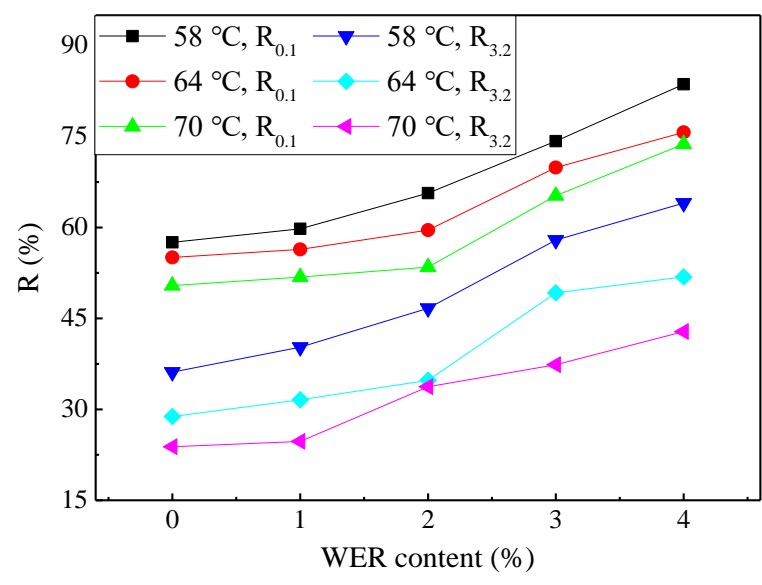

(a)

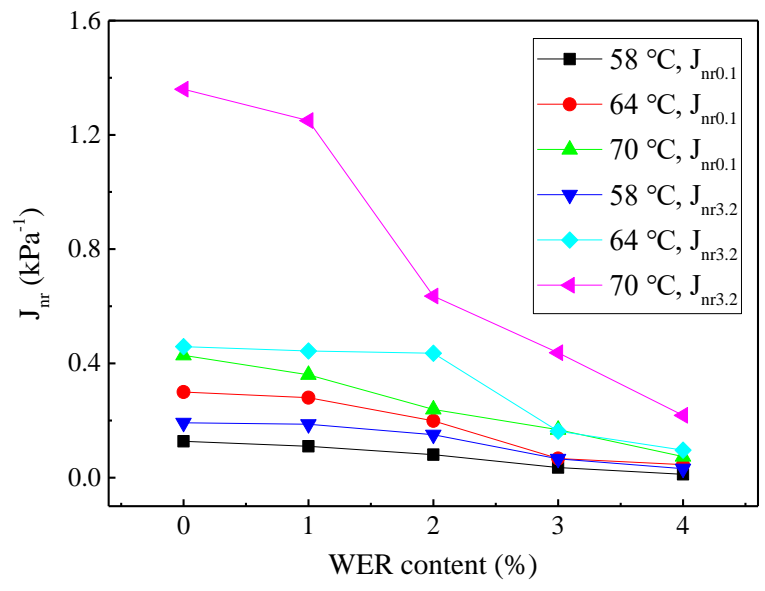

(b)

Figure 7. Creep recovery rate $\mathrm{R}$ and unrecoverable creep compliance $\mathrm{J}_{\mathrm{nr}}$ of evaporation residue of the WESAE and the SBRAE: (a) changes of R; (b) changes of $\mathrm{J}_{\mathrm{nr}}$.

The creep recovery rate $\mathrm{R}$ and unrecoverable creep compliance $\mathrm{J}_{\mathrm{nr}}$ characterize the self-healing ability and permanent deformation resistance of viscoelastic materials under repeated shear stress. Moreover, previous studies have shown that $\mathrm{J}_{\mathrm{nr}}$ has a higher correlation with the rutting resistance of the modified asphalt mixture than the rutting factor index; thus, $\mathrm{J}_{\mathrm{nr}}$ can preferably estimate the high-temperature performance of the modified asphalt [35]. Figure 7 shows that R gradually increases with the increase of WER at different temperatures, while $\mathrm{J}_{\mathrm{nr}}$ decreases gradually, indicating that the incorporation of WER improves the self-healing ability and resistance to permanent deformation of the SBRAE residue. Compared with the SBRAE residue, the $\mathrm{J}_{\mathrm{nr} 3.2}$ of the WESAE residue with $3 \%$ WER decreases to $0.1629 \mathrm{kPa}^{-1}$ at $64{ }^{\circ} \mathrm{C}$, which is equivalent to the $\mathrm{J}_{\mathrm{nr} 3.2}$ of linear styrene-butadiene-styrene (SBS) modified asphalt with 5.0\% modifier (by weight of pure asphalt) at the same temperature [36]. In summary, WESAE residues have favorable high-temperature properties, especially the WESAE residues containing $3 \%$ and $4 \%$ WER.

\subsubsection{Adhesion with the Coarse Aggregate}

Adhesion between the WESAE, SBRAE, and the coarse limestone aggregate was first measured according to the adhesion test. Next, the sample images were taken, as shown in Figure 8. The calculation results for the spalling rate $\alpha$ of the asphalt film are shown in Table 5. 


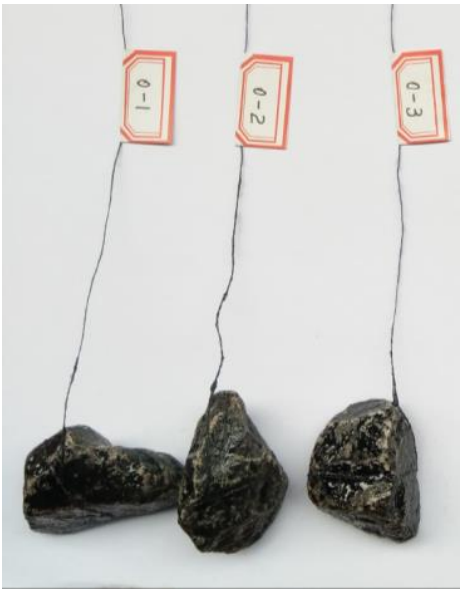

(a) $0 \%(\mathrm{SBRAE})$

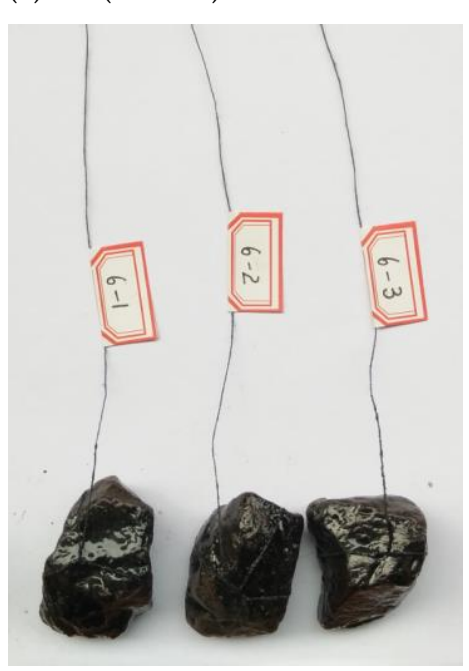

(d) $3 \%$

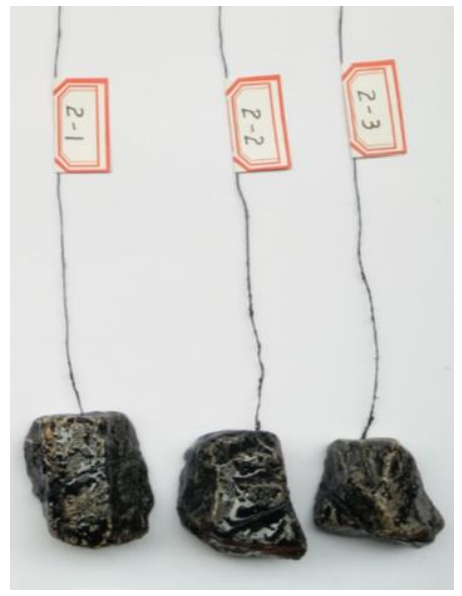

(b) $1 \%$

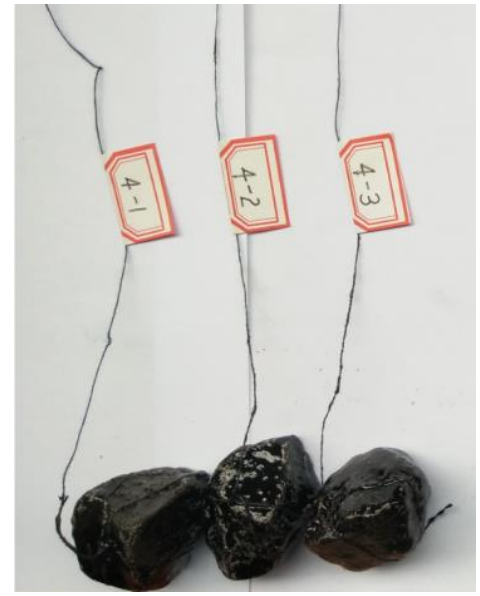

(c) $2 \%$

Figure 8. Sample images after the samples were boiled and cooled until dry.

Table 5. Test results of the adhesion between the WESAE, SBRAE, and the coarse limestone aggregate.

\begin{tabular}{|c|c|c|c|c|c|c|}
\hline \multirow{2}{*}{$\begin{array}{c}\text { WER } \\
\text { Content }(\%)\end{array}$} & \multirow{2}{*}{ Number } & \multicolumn{3}{|c|}{ Mass (g) } & \multirow{2}{*}{$\begin{array}{c}\text { Spalling } \\
\text { Rate } \alpha(\%)\end{array}$} & \multirow{2}{*}{$\begin{array}{c}\text { Average Spalling } \\
\text { Rate }(\%)\end{array}$} \\
\hline & & $\mathrm{m}_{1}$ & $\mathbf{m}_{2}$ & $\mathbf{m}_{3}$ & & \\
\hline \multirow{4}{*}{0 (SBRAE) } & $0-1$ & 23.72 & 23.86 & 23.82 & 28.57 & \multirow{3}{*}{31.16} \\
\hline & $0-2$ & 22.79 & 23.03 & 22.95 & 33.33 & \\
\hline & $0-3$ & 20.50 & 20.69 & 20.63 & 31.58 & \\
\hline & $2-1$ & 17.80 & 18.01 & 17.96 & 23.81 & \multirow{3}{*}{26.36} \\
\hline \multirow[t]{3}{*}{1} & $2-2$ & 20.61 & 20.94 & 20.85 & 27.27 & \\
\hline & $2-3$ & 16.77 & 17.02 & 16.95 & 28.00 & \\
\hline & $4-1$ & 20.15 & 20.40 & 20.35 & 20.00 & \multirow{4}{*}{19.96} \\
\hline \multirow[t]{3}{*}{2} & $4-2$ & 16.58 & 16.82 & 16.77 & 20.83 & \\
\hline & $4-3$ & 21.01 & 21.22 & 21.18 & 19.05 & \\
\hline & $6-1$ & 25.74 & 25.99 & 25.96 & 12.00 & \\
\hline \multirow[t]{3}{*}{3} & $6-2$ & 21.63 & 21.79 & 21.77 & 12.50 & \multirow[t]{2}{*}{11.87} \\
\hline & $6-3$ & 21.36 & 21.45 & 21.44 & 11.11 & \\
\hline & $8-1$ & 19.08 & 19.20 & 19.19 & 8.33 & \multirow{3}{*}{9.60} \\
\hline \multirow[t]{2}{*}{4} & $8-2$ & 20.96 & 21.10 & 21.09 & 7.14 & \\
\hline & $8-3$ & 18.70 & 18.85 & 18.83 & 13.33 & \\
\hline
\end{tabular}


As shown in Figure 8, when the content of WER does not exceed $2 \%$, the asphalt film on the aggregate surface undergoes apparent flow and agglomeration after boiling and there is a "white" substance on the aggregate surface as a result of the asphalt film having fallen off. However, when the content of WER is greater, the asphalt film on the aggregate surface is evenly distributed, does not obviously flow, and makes a good wrap for aggregates.

In addition, it can be seen from Table 5 that the incorporation of WER effectively reduces the spalling rate of the asphalt film; the spalling rate decreases with the increase of WER content. Compared with the SBRAE, the stripping rate of WESAEs with $1 \%, 2 \%, 3 \%$, and $4 \%$ WER decreases by $4.80 \%$, $11.20 \%, 19.29 \%$, and $21.56 \%$, respectively. This proves that WER allows good adhesion between the SBRAE and the aggregate. The main reason for the enhanced adhesion between the WESAE and the aggregate may be explained as follows [37]. As the water evaporates, the WER passes through asphalt molecules and crosslinks with the curing agent, forming a stable macromolecular network structure. The network structure is characterized by asphalt particles in the core and epoxy resin adsorbed on the surface, which effectively restrains the movement of the asphalt particles and prevents them from spalling from the aggregate surface.

\subsubsection{Analysis of Variance Test}

For a better understanding of the influence of WER content on the WESAE residue properties, one-way ANOVA was also implemented using SPSS software at a significance level of $95 \%$. The analysis results are listed in Table 6.

Table 6. ANOVA results of the effect of WER content on the WESAE residue properties.

\begin{tabular}{|c|c|c|c|c|c|}
\hline Properties & \multicolumn{3}{|c|}{ Dependent Variables } & F-Statistics & $\begin{array}{c}\text { Significance } \\
(p-\text { Value })\end{array}$ \\
\hline \multirow{2}{*}{ High temperature } & \multirow{2}{*}{\multicolumn{3}{|c|}{$\begin{array}{c}\text { Penetration } \\
\text { Softening point }\end{array}$}} & 1347.083 & 0.000 \\
\hline & & & & 461.650 & 0.000 \\
\hline \multirow{8}{*}{$\begin{array}{l}\text { Temperature } \\
\text { sensitivity }\end{array}$} & \multicolumn{3}{|c|}{ Enthalpy per unit mass } & 24.623 & 0.004 \\
\hline & \multirow{7}{*}{$\begin{array}{l}\text { Temperature } \\
\text { scanning test }\end{array}$} & \multirow{4}{*}{$\mathrm{G}^{*} / \sin \delta$} & $58^{\circ} \mathrm{C}$ & 42.714 & 0.000 \\
\hline & & & $64^{\circ} \mathrm{C}$ & 22.155 & 0.002 \\
\hline & & & $70^{\circ} \mathrm{C}$ & 15.352 & 0.004 \\
\hline & & & $58^{\circ} \mathrm{C}$ & 175.876 & 0.000 \\
\hline & & \multirow[t]{3}{*}{$\mathrm{R}_{0.1}$} & $64^{\circ} \mathrm{C}$ & 185.395 & 0.000 \\
\hline & & & $70^{\circ} \mathrm{C}$ & 101.112 & 0.000 \\
\hline & & & $58^{\circ} \mathrm{C}$ & 172.054 & 0.000 \\
\hline \multirow[t]{8}{*}{ Rheology } & \multirow{2}{*}{\multicolumn{2}{|c|}{$\mathrm{R}_{3.2}$}} & $64^{\circ} \mathrm{C}$ & 264.951 & 0.000 \\
\hline & & & $70^{\circ} \mathrm{C}$ & 138.875 & 0.000 \\
\hline & & \multirow{4}{*}{$\mathrm{J}_{\mathrm{nr} 0.1}$} & $58^{\circ} \mathrm{C}$ & 243.837 & 0.000 \\
\hline & & & $64{ }^{\circ} \mathrm{C}$ & 98.191 & 0.000 \\
\hline & & & $70^{\circ} \mathrm{C}$ & 422.054 & 0.000 \\
\hline & & & $58^{\circ} \mathrm{C}$ & 202.847 & 0.000 \\
\hline & & \multirow{2}{*}{$\mathrm{J}_{\mathrm{nr} 3.2}$} & $64{ }^{\circ} \mathrm{C}$ & 145.917 & 0.000 \\
\hline & & & $70^{\circ} \mathrm{C}$ & 63.910 & 0.000 \\
\hline Adhesion & & ling rate & & 55.556 & 0.000 \\
\hline
\end{tabular}

It can be seen from Table 6 that all the $p$-values are lower than 0.05 , indicating that at the $95 \%$ significance level, the content of WER has a remarkable influence on the WESAE residue in terms of high-temperature performance, temperature sensitivity, rheological properties, and adhesion with the coarse aggregate, meaning a change in the WER content will bring about striking changes in the properties of the WESAE residues. Meanwhile, Bonferroni's method was also applied to compare the means of the test data for different WER contents. Bonferroni's comparison shows that when comparing the indices in Table 6, there is a statistical difference as the content of WER reaches 3\%. This means the 3\% WER notably alters the properties of the SBRAE residue. However, for all indices, 
the statistical differences vary between the WESAE with $4 \%$ WER and WESAE with 3\% WER. In terms of enthalpy per unit mass, rutting factor $\mathrm{G}^{*} / \sin \delta$, unrecoverable creep compliance $\mathrm{J}_{\mathrm{nr} 3.2}$, and spalling rate, there are no statistical differences between the two WESAE residues. It can be concluded that when the WER reaches $4 \%$, this results in a relatively small improvement in the temperature sensitivity, rutting resistance, creep recovery capability at $3.2 \mathrm{kPa}$, and adhesion of the SBRAE residue compared to the changes at $3 \%$ WER.

\subsection{Comprehensive Performance Evaluation and Cost Analysis for WESAE}

\subsubsection{Comprehensive Performance Evaluation of WESAE}

In order to evaluate the comprehensive performance of WESAE with different contents of WER and to determine the optimum WER content, a multiobjective gray target decision-making method is adopted in this section. The decision-making method can weigh the objectives and determine the optimal scheme [38]. In this study, the decision data were constructed for the target decision model with five schemes and seven targets, as shown in Table 7. In Table 7, the cost objectives (their values are expected to be small) include the residue content difference, enthalpy per unit mass, non-recoverable creep compliance $\mathrm{J}_{\mathrm{nr} 0.1}$, spalling rate, and cost. The moderate objective (its value is expected to be moderate) is the viscosity after $12 \mathrm{~h}$ of storage, while the benefit objective (its value is expected to be large) is the softening point.

Table 7. Data for multiobjective gray target decisions.

\begin{tabular}{|c|c|c|c|c|c|c|c|c|}
\hline \multirow{4}{*}{ Schemes } & \multirow{4}{*}{$\begin{array}{c}\text { WER } \\
\text { Content } \\
(\%)\end{array}$} & \multicolumn{7}{|c|}{ Performance Indices } \\
\hline & & \multicolumn{7}{|c|}{ Objectives k } \\
\hline & & $k=1$ & $k=2$ & $k=3$ & $k=4$ & $k=5$ & $k=6$ & $\mathbf{k}=7$ \\
\hline & & $\begin{array}{c}\text { Residue } \\
\text { Content } \\
\text { Difference } \\
(\%)\end{array}$ & $\begin{array}{c}\text { Viscosity at } \\
12 \mathrm{H} \text { of } \\
\text { Storage (s) }\end{array}$ & $\begin{array}{c}\text { Softening } \\
\text { Point } \\
\left({ }^{\circ} \mathrm{C}\right)\end{array}$ & $\begin{array}{c}\text { Enthalpy } \\
\text { per Unit } \\
\text { Mass }\left(\mathrm{J} \cdot \mathrm{g}^{-1}\right)\end{array}$ & $\begin{array}{c}\mathrm{J}_{\mathrm{nr} 0.1} \text { at } \\
64{ }^{\circ} \mathrm{C} \\
\left(\mathrm{kPa}^{-1}\right)\end{array}$ & $\begin{array}{l}\text { Spalling } \\
\text { Rate (\%) }\end{array}$ & $\begin{array}{c}\text { WESAE } \\
\text { Cost } \\
\text { (yuan/kg) }\end{array}$ \\
\hline 1 & 0 & 0.7 & 24 & 52.5 & 0.365 & 0.2994 & 31.16 & 3.676 \\
\hline 2 & 1 & 0.4 & 27 & 53 & 0.289 & 0.2801 & 26.36 & 4.083 \\
\hline 3 & 2 & 0.6 & 40 & 56 & 0.268 & 0.1987 & 19.96 & 4.436 \\
\hline 4 & 3 & 0.8 & 47 & 61.5 & 0.151 & 0.0669 & 11.87 & 4.789 \\
\hline 5 & 4 & 1.6 & 66 & 63.5 & 0.106 & 0.0456 & 9.60 & 5.141 \\
\hline
\end{tabular}

(1) Establishment and Standardization of Sample Matrix

According to the decision data listed in Table 7, the sample matrix $U$ is first established as follows.

$$
\mathrm{U}=\mathrm{u}_{\mathrm{ij}}=\left[\begin{array}{ccccccc}
0.7 & 24 & 52.5 & 0.365 & 0.2994 & 31.16 & 3.676 \\
0.4 & 27 & 53 & 0.289 & 0.2801 & 26.36 & 4.083 \\
0.6 & 40 & 56 & 0.268 & 0.1987 & 19.96 & 4.436 \\
0.8 & 47 & 61.5 & 0.151 & 0.0669 & 11.87 & 4.789 \\
1.6 & 66 & 63.5 & 0.106 & 0.0456 & 9.60 & 5.141
\end{array}\right]
$$

Because different objectives have different meanings and dimensions, they often cannot be compared directly. In order to make the different objectives comparable, the sample matrix $U$ is then standardized as decision matrix $\mathrm{R}$ according to Equation (2) provided in the literature [39]. In Equation (2), when $\mathrm{k}$ is 2, the corresponding objective is a moderate objective that is expected to have a moderate value of 36 (the standard viscosity should be between 12 and 60). Thus, when the sample value $\mathrm{u}_{\mathrm{ij}}$ is between 12 and 36 , the decision value is defined as $\left(\mathrm{u}_{\mathrm{ij}}-12\right) /(36-12)$; when the sample value $u_{i j}$ is greater than 36 , the decision value is defined as $\left(60-u_{i j}\right) /(60-36)$. 


$$
\begin{aligned}
& \mathrm{R}=\mathrm{r}_{\mathrm{ij}}=\left\{\begin{array}{cc}
\frac{\max _{\mathrm{i}} \max _{\mathrm{j}}\left\{\mathrm{u}_{\mathrm{ij}}\right\}-\mathrm{u}_{\mathrm{ij}}}{\max _{\mathrm{i}} \max _{\mathrm{j}}\left\{\mathrm{u}_{\mathrm{ij}}\right\}-\min _{i} \min _{\mathrm{j}}\left\{\mathrm{u}_{\mathrm{ij}}\right\}} & \mathrm{k}=\{1,4,5,6,7\} \\
\frac{\mathrm{u}_{\mathrm{ij}}-12}{24} & \mathrm{k}=2 \text { and } 12 \leq \mathrm{u}_{\mathrm{ij}} \leq 36 \\
\frac{60-\mathrm{u}_{\mathrm{ij}}}{24} & \mathrm{k}=2 \text { and } \mathrm{u}_{\mathrm{ij}} \geq 36 \\
\frac{\mathrm{u}_{\mathrm{ij}}-\min _{\mathrm{i}} \min _{\mathrm{j}}\left\{\mathrm{u}_{\mathrm{ij}}\right\}}{\max _{\mathrm{i}} \max _{\mathrm{j}}\left\{\mathrm{u}_{\mathrm{ij}}\right\}-\min _{\mathrm{i}} \min _{\mathrm{j}}\left\{\mathrm{u}_{\mathrm{ij}}\right\}} & \mathrm{k}=\{3\}
\end{array}\right. \\
& \mathrm{R}=\mathrm{r}_{\mathrm{ij}}=\left[\begin{array}{ccccccc}
0.750 & 0.500 & 0.000 & 0.000 & 0.000 & 0.000 & 1.000 \\
1.000 & 0.625 & 0.045 & 0.293 & 0.076 & 0.223 & 0.722 \\
0.833 & 0.833 & 0.318 & 0.375 & 0.397 & 0.519 & 0.481 \\
0.667 & 0.542 & 0.818 & 0.826 & 0.916 & 0.895 & 0.240 \\
0.000 & -0.25 & 1.000 & 1.000 & 1.000 & 1.000 & 0.000
\end{array}\right]
\end{aligned}
$$

(2) Determination of Bull's Eye and Bull's Eye Distance

The decision-making gray target is generally a spherical gray target composed of the $\mathrm{k}$ (the number of objectives) dimension space, while its bull's eye is the ideal optimal values of various schemes for each objective after standardization. A spherical gray target model is shown in Equation (3) [40].

$$
\mathrm{S}^{\mathrm{k}}=\left\{\left[\mathrm{r}_{1}, \mathrm{r}_{2}, \cdots, \mathrm{r}_{\mathrm{k}}\right] \mid\left(\mathrm{r}_{1}-\mathrm{r}_{01}\right)^{2}+\left(\mathrm{r}_{2}-\mathrm{r}_{02}\right)^{2}+\cdots+\left(\mathrm{r}_{\mathrm{k}}-\mathrm{r}_{0 \mathrm{k}}\right)^{2} \leq \mathrm{S}^{2}\right\}
$$

From the standardized decision matrix $R$, the bull's eye is first chosen as $r_{0}=\left\{r_{01}, r_{02}, r_{03}, r_{04}, r_{05}\right.$, $\left.\mathrm{r}_{06}, \mathrm{r}_{07}\right\}=\{1.000,0.833,1.000,1.000,1.000,1.000,1.000\}$. Then, the distances between different schemes and bull's eye (i.e., bull's eye distances of different schemes) are calculated according to Equation (4), in which the $\mathrm{SD}_{\mathrm{i}}$ is the distance between i-th scheme and bull's eye (i.e., bull's eye distance of i-th scheme).

$$
\mathrm{SD}_{\mathrm{i}}=\left|\mathrm{r}_{\mathrm{i}}-\mathrm{r}_{0}\right|=\sqrt{\sum_{\mathrm{j}=1}^{7}\left(\mathrm{r}_{\mathrm{ij}}-\mathrm{r}_{0 \mathrm{j}}\right)^{2}} \quad \mathrm{i}=\{1,2,3,4,5\}
$$

The bull's eye distance of the first scheme is calculated as $\mathrm{SD}_{1}=\left|\mathrm{r}_{1}-\mathrm{r}_{0}\right|=\left[(0.750-1.000)^{2}+\right.$ $\left.(0.500-0.833)^{2}+4(0.000-1.000)^{2}\right]^{1 / 2}=2.043$. Similarly, the bull's eye distances of the other schemes are calculated as $\left\{\mathrm{SD}_{2}, \mathrm{SD}_{3}, \mathrm{SD}_{4}, \mathrm{SD}_{5}\right\}=\{1.729,1.322,0.924,1.781\}$.

(3) Comprehensive Performance Evaluation and Determination of WER Content

The bull's eye distance represents the distance between the target vector of each scheme and the target vector of the ideal optimal scheme, where a smaller distance indicates a better scheme [38]. As the bull's eye distance is denoted as $\mathrm{SD}_{\mathrm{i}}$, the bull's eye distances of the five schemes are ranked as $\mathrm{SD}_{4}<\mathrm{SD}_{3}<\mathrm{SD}_{2}<\mathrm{SD}_{5}<\mathrm{SD}_{1}$, indicating that the objectives of the fourth scheme are optimally balanced; that is, WESAE with $3 \%$ WER shows the best overall performance. Accordingly, the optimum content of WER is determined to be $3 \%$ of the WESAE by weight.

\subsubsection{Cost Analysis of WESAE}

The multiobjective gray target decision-making analysis indicates that the WESAE with $3 \%$ WER shows the best overall performance. The cost of the WESAE is also important. In order to analyze the cost of the WESAE, three kinds of asphalt emulsions-namely the neat asphalt emulsion, SBRAE, and styrene-butadiene-styrene (SBS) latex modified asphalt emulsion, all of which are commercially used in pavement engineering-were selected for comparison. At present, the market prices of the main raw materials of neat asphalt, SBR latex modifier, SBS latex modifier, WER modifier, and the curing agent are 3500, 16,500, 20,000, 21,000, and 21,000 yuan/t, respectively. According to previous studies, the optimal contents of SBR latex and SBS latex modifiers are recommended to be $3 \%$ and $4 \%$, respectively, of the total weight of the modified asphalt emulsion $[13,14,41]$. Thus, the initial costs 
for the neat asphalt emulsion, SBRAE, SBS latex modified asphalt emulsion, and WESAE with 3\% WER with the materials costs and electricity expenses taken into account were calculated to be 3181 , 3676,3711 , and 4789 yuan/t, respectively, when prepared in the laboratory. This means that if one ton of the WESAE with 3\% WER is prepared, the cost will increase by 1608 yuan/t compared to neat asphalt emulsion, 1113 yuan/t compared to SBRAE, and 1078 yuan/t compared to SBS latex modified asphalt emulsion. However, the use of WESAE can improve the pavement performance and prolong the service life of the pavement; thus, the WESAE may have a lower total life cycle cost.

\subsection{Modification Mechanism Analysis of WER}

The test results above demonstrate that the incorporation of the WER modifier improves the properties of the SBRAE residue, but it is unknown whether the WER reacts with the SBRAE during the blending process. Therefore, in this part, the FTIR test is conducted on the SBRAE and the WESAE samples to ascertain the modification mechanism of the WER modifier. Figure 9 shows the infrared spectra for WESAE with $1 \%$ and 3\% WER and for SBRAE.

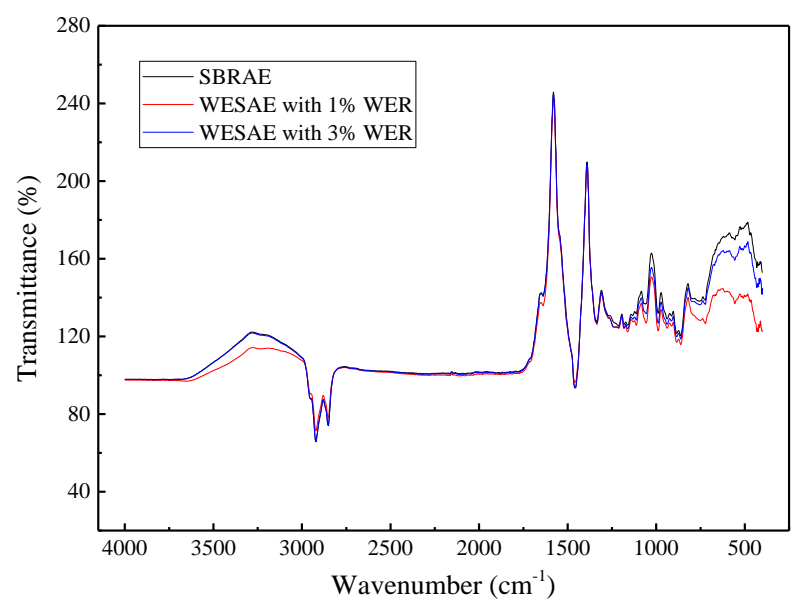

Figure 9. Infrared spectra for WESAE with $1 \%$ and $3 \%$ WER and for SBRAE.

As illustrated in Figure 9, the peaks at 2952, 2921, and $2852 \mathrm{~cm}^{-1}$ are caused by the stretching vibration of methylene $\left(-\mathrm{CH}_{2}-\right)$, which are judged as the characteristic group of carbon chains in asphalt [42]. The sharp and strong peak at $1460 \mathrm{~cm}^{-1}$ is the result of the bending vibration of $\mathrm{C}-\mathrm{H}$ in methyl $\left(-\mathrm{CH}_{3}\right)$ or in methylene $\left(-\mathrm{CH}_{2}-\right)$, and the peak near $1334 \mathrm{~cm}^{-1}$ is formed by the bending vibration of methyl $\left(-\mathrm{CH}_{3}\right)$. These are also the characteristic absorption vibration peaks of carbon chains in asphalt [43]. The peak at $915 \mathrm{~cm}^{-1}$ is the absorption vibration peak of the epoxy group [43], and it can be seen in Figure 9 that the three emulsions contain the functional group. The peak at $860 \mathrm{~cm}^{-1}$ is formed by the bending vibration outside of the $=\mathrm{C}-\mathrm{H}-$ plane on the benzene ring. It has a characteristic disc-shaped aromatic tablet with a high polycondensation peri-configuration [17]. It is also observed that the three emulsions contain the $=\mathrm{C}-\mathrm{H}-$ functional group.

According to Figure 9, compared with the infrared spectrum of SBRAE, the infrared spectrum of WESAE presents almost the same curve. This means that no new absorption peak appears in the infrared spectrum of WESAE, indicating that WER and SBRAE are physically blended; there is no chemical reaction in the blending process.

\section{Summary and Conclusions}

This paper investigated the storage stability, workability, and evaporation residue properties of the WESAE; evaluated the comprehensive performance of the WESAE; and revealed the modification mechanism of the WER modifier. The main findings from this study can be summarized as follows: 
- The content of WER has a significant effect on the storage stability of WESAE. A small amount of WER can slightly improve the storage stability compared to the SBRAE, but an excessive dosage will result in an obvious decrease in the storage stability of the WESAE. When the WER content reaches $4 \%$, the one-day storage stability of the WESAE exceeds the specification limit.

- When the WER content reaches $4 \%$, the microsphere particles of the WESAE agglomerate after the WESAE is stored for $24 \mathrm{~h}$. Furthermore, the average particle diameter and the particle diameter distribution width of the WESAE with $4 \%$ WER reach 19.456 and $22 \mu \mathrm{m}$ at $24 \mathrm{~h}$ of storage, respectively, which are far greater values than for SBRAE at the same storage time.

- The workability of the WESAE is affected by the WER content and storage time. At any storage time, the viscosity of the WESAE gradually increases with the increase of WER content; the sensitivity of the WESAE viscosity to time is gradually enhanced by increasing the WER content. The addition of 3\% WER content can be regarded as the maximum amount to guarantee viscosity, and the prepared WESAE with $3 \%$ WER should be used within $24 \mathrm{~h}$.

- The content of WER has a remarkable impact on the WESAE residue properties in terms of temperature performance, thermal stability, rheological properties, and adhesion with the aggregate. It is evident that 3\% WER improves these properties in the SBRAE residue.

- The WESAE with 3\% WER shows the most comprehensive performance. Thus, the optimal WER content considering storage stability, workability, residue properties, and cost is determined to be $3 \%$ of the WESAE by weight.

- The modification of SBRAE by WER is a physical method; no chemical reaction occurs in the blending process.

In conclusion, WESAE with 3\% WER meets the requirements for storage stability and workability as outlined in the specifications. Furthermore, compared with SBRAE, its associated evaporation residue has excellent high-temperature performance, thermal stability, rheological properties, and adhesion on coarse aggregates. Therefore, it can be applied in microsurfacing and cold recycled mixtures in special environments (such as high-temperature and rainy areas). Nevertheless, the study characterized the properties of the WESAE from a longitudinal perspective. Further research is necessary to investigate the properties of different kinds of modified asphalt emulsions for comparison, and the results of laboratory research should be validated by paving the test roads.

Author Contributions: Methodology, J.Y.; formal analysis, J.Y.; investigation, Y.F.; data curation, J.Y.; writing-original draft preparation, J.Y.; writing-review and editing, Z.Z.; supervision, Y.F. and Y.L.; funding acquisition, Z.Z. and Y.L. All authors have read and agreed to the published version of the manuscript.

Funding: The work described herein is part of a research project on "Research on Application Technology of Self-Melting Snow and Anti-Freezing Asphalt Pavement", funded by the Transportation Science and Technology in Shaanxi Province under Grant No. KY17-02. This research has also been funded by the Science and Technology Project of Henan Province (Grant No. 202102310589).

Conflicts of Interest: The authors confirm that there are no conflicts of interest.

\section{References}

1. He, Y.H.; Zhang, R.H. Application of emulsified asphalt modified water-epoxy resin to maintenance of highway. New Build. Mater. 2007, 05, 37-40. (In Chinese)

2. Chen, Z.D.; Zhang, Z.; Wu, Y.J.; Niu, X.H.; Chen, Z.F. Application of waterborne epoxy emulsified asphalt. Road Mach. Constr. Mech. 2017, 34, 23-28. (In Chinese)

3. Malladi, H.; Castorena, C. Field measurements of emulsion application rates and pavement emulsion absorption in tack coats and chip seals. Constr. Build. Mater. 2019, 218, 701-711. [CrossRef]

4. Galaviz-Gonzalez, J.R.; Cueva, D.A.; Covarrubias, P.L.; Palacios, M.Z. Bonding evaluation of asphalt emulsions used as tack coats through shear testing. Appl. Sci. Basel 2019, 9, 1727. [CrossRef]

5. Abedini, M.; Hassani, A.; Kaymanesh, M.R.; Yousefi, A.A. The rheological properties of a bitumen emulsion modified with two types of SBR latex. Petrol. Sci. Technol. 2016, 34, 1589-1594. [CrossRef] 
6. Chen, X.H.; Liu, S.; Sun, L.F. Preparation and properties of emulsion asphalt modified by nano silica/SBR composite. China Rubber Ind. 2007, 54, 337-340. (In Chinese)

7. Abd El-Rahman, A.M.M.; El-Shafie, M.; Abo-Shanab, Z.L.; El-Kholy, S.A. Modifying asphalt emulsion with different types of polymers for surface treatment applications. Petrol. Sci. Technol. 2017, 35, 1473-1480. [CrossRef]

8. Ji, J.; Liu, L.H.; Suo, Z.; Xu, Y.; Yang, S.; Xu, S.F. Performance of micro-surfacing with waterborne epoxy resin modified emulsified asphalt. J. Chang'an Univ. (Nat. Sci. Ed.) 2017, 37, 23-30. (In Chinese)

9. Hou, S.G.; Chen, C.; Zhang, J.H.; Shen, H.J.; Gu, F. Thermal and mechanical evaluations of asphalt emulsions and mixtures for microsurfacing. Constr. Build. Mater. 2018, 191, 1221-1229. [CrossRef]

10. Qian, H.T.; Gao, S.Q. Application study on waterborne epoxy emulsified asphalt for pavement seal coat. Petrol. Asph. 2015, 29, 40-43. (In Chinese)

11. Zhang, Q.; Hao, P.W.; Bai, Z.Y. Properties of asphalt emulsion modified with waterborne epoxy resin and SBR composite. New Build. Mater. 2015, 42, 43-46. (In Chinese)

12. Li, X.J.; Bi, W.L.; Shi, F.Z.; Lv, J.W.; Hui, Z.F. Research on the compound modification effect of waterborne epoxy resin on SBR emulsified asphalt. J. Chongqing Jiaotong Univ. (Nat. Sci.) 2018, 37, 40-46. (In Chinese)

13. Zhang, Q.; Xu, Y.H.; Wen, Z.G. Influence of waterborne epoxy resin content on performance of waterborne epoxy resin compound SBR modified emulsified asphalt for tack coat. Constr. Build. Mater. 2017, 153, 774-782. [CrossRef]

14. Chang, R.T.; Du, S.J.; Pei, Q.; Guo, Y.Y.; Pang, J.Y. Effect of SBR on the rheological properties of emulsified asphalt. J. Chongqing Jiaotong Univ. (Nat. Sci.) 2016, 35, 38-41. (In Chinese)

15. Zhou, W.F.; Dong, L.W.; Song, X.Y.; Yang, Z.W. Study on high-temperature performance of waterborne epoxy modified emulsified asphalt. J. Chongqing Jiaotong Univ. (Nat. Sci.) 2019, 38, 55-59. (In Chinese)

16. Li, X.J.; Hui, Z.F.; Yan, H.Z.; Zhang, H. Experimental analysis of the adhesive performance of waterborne epoxy modified emulsified asphalt. J. Build. Mater. 2019, 22, 160-166. (In Chinese)

17. Li, R.; Leng, Z.; Zhang, Y.; Ma, X. Preparation and characterization of waterborne epoxy modified bitumen emulsion as a potential high-performance cold binder. J. Clean. Prod. 2019, 235, 1265-1275. [CrossRef]

18. Thermal Analysis and Thermo-Physical Instruments Home Page. Available online: http://www.ngb-netzsch. com.cn/products/dsc.html (accessed on 24 March 2020).

19. ASTM Standard 2018. Standard Test Method for Enthalpies of Fusion and Crystallization by Differential Scanning Calorimetry, E793-06; ASTM International: West Conshohocken, PA, USA, 2018.

20. Anton Paar Home Page. Available online: https://www.anton-paar.com/corp-en/ (accessed on 24 March 2020).

21. AASHTO Standard 2019. Standard Method of Test for Multiple Stress Creep Recovery (MSCR) Test of Asphalt Binder Using a Dynamic Shear Rheometer (DSR), T350-19; American Association of State Highway and Transportation Officials (AASHTO): Washington, DC, USA, 2019.

22. Hassanpour-Kasanagh, S.; Ahmedzade, P.; Fainleib, A.M.; Behnood, A. Rheological Properties of asphalt binders modified with recycled materials: A comparison with Styrene-Butadiene-Styrene (SBS). Constr. Build. Mater. 2020, 230, 117047. [CrossRef]

23. Gu, Y.; He, L.H.; Yang, F. Research review on the compatibility of waterborne epoxy emulsified asphalt. Petrol. Asph. 2018, 32, 1-9. (In Chinese)

24. Meng, Y.; Dong, C.J. Analysis on effect factors of emulsified asphalt storage stability. Petrol. Asph. 2015, 29, 31-34. (In Chinese)

25. Zhang, Q.; Hao, P.W.; Bai, Z.Y. Research on preparation and adhesion of emulsified asphalt modified with waterborne epoxy resin. J. Highw. Transp. Res. Dev. 2015, 32, 9-14. (In Chinese)

26. Chinese Industry Standard 2004. Technical Specification for Construction of Highway Asphalt Pavements, JTG F40-2004; Ministry of Transport of the People's Republic of China (MOT): Beijing, China, 2004.

27. Abdullah, G.M.S.; Wahhab, H.I.A.A. Stabilisation of soils with emulsified sulphur asphalt for road applications. Road Mater. Pavement Des. 2019, 20, 1228-1242. [CrossRef]

28. Querol, N.; Barreneche, C.; Cabeza, L.F. Asphalt emulsion formulation: State of the art of formulation, properties and results of HIPR emulsions. Constr. Build. Mater. 2019, 212, 19-26. [CrossRef]

29. Zheng, M.L.; Fan, X.P.; Li, H.Y.; Lin, X.Y.; Liu, P. Research progress of waterborne epoxy emulsified asphalt for road. China Sci. Paper 2019, 14, 821-829. (In Chinese) 
30. Cao, W.D.; Liu, S.T.; Li, X.X. Laboratory evaluation of the effect of composite modifier on the performance of asphalt concrete mixture. Constr. Build. Mater. 2017, 155, 363-370. [CrossRef]

31. Xue, W. Statistical Analysis and SPSS Application, 5th ed.; China Renmin University Press: Beijing, China, 2017; ISBN 978-73-0024-609-3.

32. Ding, H.B.; Qiu, Y.J.; Rahman, A. Low-temperature reversible aging properties of selected asphalt binder based on thermal analysis. J. Mater. Civil Eng. 2019, 31, 04018402. [CrossRef]

33. Xu, L.; Xiong, W.H. Analysis for dependency between eigenvalues of DSC endothermic peak of asphalt and temperature susceptibility indices. Technol. Highw. Transp. 2014, 34-36. (In Chinese)

34. Behnood, A. Application of rejuvenators to improve the rheological and mechanical properties of asphalt binders and mixtures: A review. J. Clean. Prod. 2019, 231, 171-182. [CrossRef]

35. Lv, Q.; Huang, W.D.; Sadek, H.; Xiao, F.P.; Yan, C.Q. Investigation of the rutting performance of various modified asphalt mixtures using the Hamburg Wheel-Tracking Device test and Multiple Stress Creep Recovery test. Constr. Build. Mater. 2019, 206, 62-70. [CrossRef]

36. Tang, N.P.; Huang, W.D. High temperature performance evaluation and grading of SBS modified asphalt based on multiple stress creep recovery test. J. Build. Mater. 2016, 19, 665-671. (In Chinese)

37. Hu, C.C.; Zhao, J.Y.; Leng, Z.; Partl, M.N.; Li, R. Laboratory evaluation of waterborne epoxy bitumen emulsion for pavement preventative maintenance application. Constr. Build. Mater. 2019, 197, 220-227. [CrossRef]

38. Chen, Q.; Wang, C.H.; Fu, H.; Zhang, L. Durability evaluation of road cooling coating. Constr. Build. Mater. 2018, 190, 13-23. [CrossRef]

39. Zhang, W.J.; Yuan, H.P. A weighted multi-objective gray target decision model for selecting an optimum ESCO. Chin. J. Manag. Sci. 2019, 27, 179-186. (In Chinese)

40. Shen, A.Q.; Chen, X.; Guo, Y.C.; Li, P. Road performance evaluate on effects of steel slag asphalt mixture based on grey target decision. Bull. Chin. Ceram. Soc. 2019, 38, 1245-1252. (In Chinese)

41. Chen, J.J. Comparison of SBS latex replacement SBR latex used in modified emulsified asphalt. Petrol. Asph. 2017, 31, 18-21. (In Chinese)

42. Gu, Y.; Tang, B.M.; He, L.H.; Yang, F.; Wang, H.; Ling, J.M. Compatibility of cured phase-inversion waterborne epoxy resin emulsified asphalt. Constr. Build. Mater. 2019, 229, 116942. [CrossRef]

43. Zhou, Q.W.; Ling, T.Q.; Hao, Z.H.; Wu, X.L.; Li, L.; Xu, G.H. Feature analysis of waterborne epoxy resin-emulsified asphalt blend. J. Build. Mater. 2018, 21, 414-419. (In Chinese) 